\title{
Liste der Fahrtreppenfirmen
}

(Stellt keine Vollständigkeit dar, Stand Juli 2017)

Schindler Aufzüge und Fahrtreppen GmbH, 12105 Berlin

Otis GmbH \& Co. OHG, 13500 Berlin

ThyssenKrupp Fahrtreppenwerk GmbH, 22113 Hamburg

Kone GmbH Aufzüge und Rolltreppen, 30179 Hannover

Geyssel Fahrtreppenservice GmbH, 50739 Köln 